\title{
PRODUÇÃO DE SEMENTES DE BATATA-DOCE, POR FECUNDAÇÕES ARTIFICIAIS, EM CASA DE VEGETAÇÃO ${ }^{1}$ )
}

\author{
DOMINGOS ANTONIO MONTEIRO $\left(^{2}\right)$
}

\begin{abstract}
RESUMO
No período de 1970-1977, estudou-se a produção de sementes verdadeiras de batata-doce (Ipomoea batatas (L.) Lam.), por fecundaçōes artificiais em condiçōes de casa de vegetação, cultivando-se segmentos de ramas com botðes florais em vasos com água. Os resultađos evidenciaram diferença de comportamento dos genótipos quanto à capacidade de produçăo de sementes. $O$ genótipo SRT 252 (Rama Grossa) foi o que melhor se comportou como planta feminina, com formação de $57,40 \%$ de cápsulas quanđo cruzado com outros genótipos e 40,20\% quando autofecundado.

Termos de indexạ̧äo: batata-doce, Ipomoea batatas (L.) Lam., genótipos, fecunđação artificial, compatibilidade, sementes.
\end{abstract}

\section{ABSTRACT \\ SEED SETTING OF SWEET POTATO HAND POLLINATED UNDER GRENHOUSE CONDITIONS}

Seed setting of five sweet potato genotypes: SRT 72-Jacareí; SRT 248; SRT 252-Rama Grossa; IAC 66-118-Monalisa and IAC 3-4-Irani was studied under greenhouse conditions. Flowers from vine cuttings growing in water were hand pollinated. All five lines functioned about equally well as pollen parents but there were significant differences in their ability to function as seed parents. Cultivars SRT 248 and SRT 72 when used as female showed a low ability to seed production both when selfed and crossed. Such ability appeared to be a varietal characteristic which affected seed set. Differences were found between the percentage of seed set of open and cross-pollinated flowers. Self incompatibility was observed for four cultivars. The highest degree of self compatibility was showed by the cultivar SRT 252. There was an observed decline in seed set during the month of June, with the highest seed set during April.

Index terms: sweet potato, Ipomoen batatas (L.) Lam., breeding lines, seed setting, compatibility, pollination.

A batata-doce, encontrada em Cuba em 1492, foi introduzida na Espanha em 1526 e espalhada pelo mundo durante os séculos XVI e XVII (Groth, 1911).

Os primeiros sucessos nos programas de melhoramento da batata-doce nos EUA foram conquistados em 1937, pela induçáo de florescimento, estudos de técnicas de melhoramento e fatores que afetam a produção de sementes (Hernandez \& Miller, 1962).

No Japão, foi introduzida no início do século XVII e se popularizou por sua resistência aos tufôes, às secas e às guerras. $\mathbf{O}$ melhoramento teve início antes da Segunda Guerra Mundial, com sementes

( ${ }^{1}$ ) Trabalho recebido para publicação em 29 de janeiro e aceito em 26 de agosto de 1992.

( ${ }^{2}$ Seção de Raízes e Tubérculos, Instituto Agronômico (IAC), Caixa Postal 28, 13001-970 Campinas (SP). 
oriundas de regiōes onde seu florescimento e sua frutificação eram naturais. Após a guerra, as sementes passaram a ser obtidas em casas de vegetação (Fujise, 1970).

Nas condiçōes de Campinas (SP), a batata-doce floresce e frutifica naturalmente. As fecundaçōes em condiçōes de campo, além de operosas, não foram bem sucedidas, de modo que, no presente trabalho, procurou-se estudar a viabilidade de produção de sementes em diferentes genótipos em condições de casa de vegetação, com base em resultados preliminares de Breda Filho (1963).

\section{Material e Métodos}

Realizaram-se os experimentos quatro vezes no período de 1969-1977, com castraçōes e polinizaçōes nos horários e métodos propostos por Tioutine (1935) e Hernandez \& Miller (1962), a saber: após a retirada da corola que ainda se encontrava fechada, as flores que seriam usadas como femininas eram emasculadas das 14 às 19 horas e as polinizaçōes, efetuadas das 6 às 9 horas do dia seguinte, com modificações quanto ao ambiente, sistema de condução (Breda Filho, 1962) e polinização. Assim, ramas de batata-doce de $40 \mathrm{~cm}$ de comprimento de cinco genótipos SRT 72-Jacareí, SRT 248, SRT 252-Rama Grossa, IAC 66-118-Monalisa e IAC 3-4-Irani, com botões florais, foram colhidas em abril/maio de cada ano, colocadas em frascos de vidro de boca larga contendo água e mantidas em ambiente protegido de insetos. As polinizações eram efetuadas até vinte dias após o início das polinizaçōes de cada haste envasada: o pólen dos progenitores masculinos era retirado das anteras com o auxílio de uma miniespátula sobre a falangeta do dedo indicador, colocado sobre os estigmas das plantas-femininas e delicadamente comprimidos com os dedos polegar, indicador e médio de uma das mãos e $o$ indicador da outra. Após essa operação de polinização, a flor recebia uma etiqueta numerada de identificação.

Diariamente, foram mantidas e identificadas flores sem emasculação e emasculadas sem polinização, para controle da polinização, uma vez que as flores e os vasos não eram protegidos individualmente por sacos protetores.

\section{Resultados e Discussão}

Os dados obtidos mostram que, nas condições de casa de vegetação e em ambiente protegido de insetos, não ocorreram polinizaçōes naturais, encontrando-se no quadro 1 os resultados dos cruzamentos e autofecundações.

Houve grande diferença entre os genótipos quanto à capacidade de produção de sementes. Assim, SRT 248 e SRT 72-Jacareí comportaram-se pessimamente como mães, enquanto SRT 252 e IAC 3-4 funcionaram satisfatoriamente.

Em média, os genótipos estudados apresentaram comportamento semelhante quando usados como plantas polinizadoras, embora o tipo de cruzamento apresente um efeito significativo sobre a habilidade de produção de sementes. Assim, as combinaçōes IAC 66-118 x SRT 252, IAC 3-4 x SRT 252 e IAC 66-118 x IAC 3-4 foram melhores que as demais - Quadro 1.

Quanto às autofecundaçōes, os resultados do presente estudo diferem dos obtidos por Montelaro \& Miller (1951) que constataram auto-incompatibilidade nas linhagens testadas, enquanto o genótipo SRT 252 apresentou alto grau de autocompatibilidade, evidenciando a possibilidade de autocompatibilidade em batata-doce.

A formação de sementes, considerando-se os cruzamentos entre si, IAC 66-118, IAC 3-4 e SRT 252, como em Montelaro \& Miller (1951), foram maiores no início do outono, abril, $60 \%$, caindo em maio para $40 \%$ e no fim para $10 \%$, junho.

Ressalte-se ainda que, embora não haja possibilidade de discutir a influência das modificaçōes incorporadas ao presente método em relação aos propostos por Tioutine (1935) e Miller (1939), dadas as variações existentes entre os genótipos quanto à habilidade para produzir sementes, essa nova maneira de produção de sementes verdadeiras de batata-doce por polinizaçōes artificiais e controladas mostrou-se relativamente prática e eficaz. 
Quadro 1. Porcentagem de formação de frutos com sementes, mediante polinizações artificiais e controladas, em cinco genótipos de batata-doce, quando usados como plantas femininas e masculinas

Femininas

Masculinas

SRT 248

SRT 252

SRT 72

IAC 66-118

IAC 3-4

Média

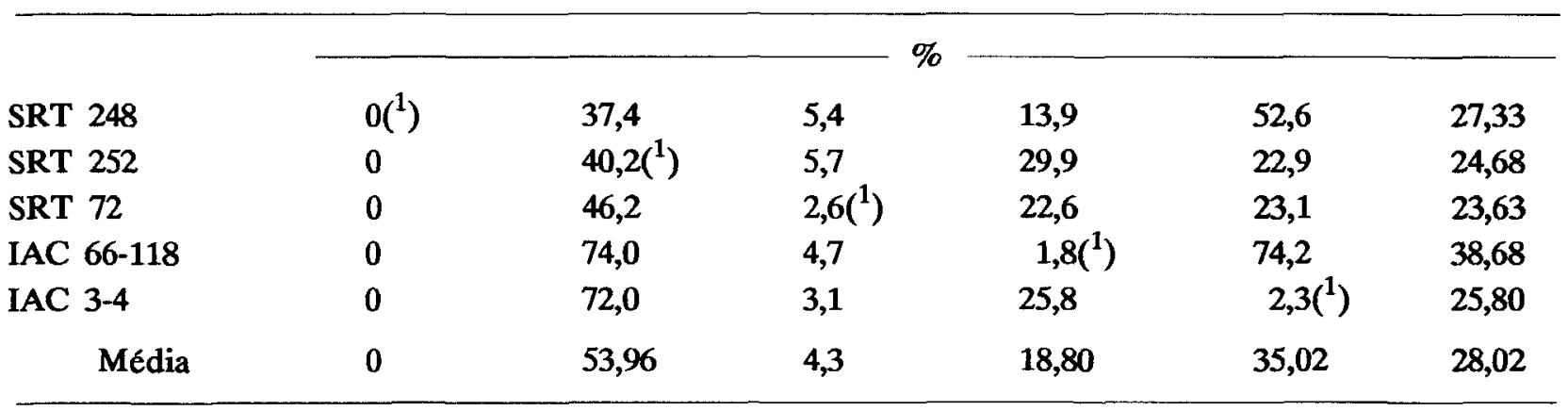

(1) Autofecundação.

\section{REFERENCIAS BIBLIOGRÁFICAS}

BREDA FILHO, J. Batata-doce e cará: relatório dos trabalhos experimentais referente ao ano agricola 1961/62. Campinas, Instituto Agronômico, 1963. 19p. (Datilografado)

FUJSE, $K$ Sweet potato and its breeding efficacy in Japan. In: INTERNATIONAL SYMPOSIUM ON TROPICAL ROOT AND TUBER CROPS, 2., Honolulu, 1970. Proceedings. Honolulu, University of Hawaii-College of Tropical Agriculture, 1970. v.1, p.19-21.

GROTH, B.H.A. The sweet potato. Philadelphia, University of Pennsytvania, 1911. 104p. (Contributions from the Botanical Laboratory, v.4, n.1.)
HERNANDEZ, T.P. \& MILLER, J.C. Self-and cross-incompatibilities in the sweet potato. Proceedings of the American Society for Horticultural Science, Beltsville, 81:428-433, 1962.

MILLER, J.C. Further studies and technic used in sweet potato breeding in Louisiana. Journal of Heredity, Washington, D.C., 30(11):485-492. 1939.

MONTEI ARO, J. \& MILLER, J.C. A study of some factors affecting seed setting in the sweet potato. Proceedings of the American Society for Horticultural Science, Ithaca, 57:329$-334,1951$.

TIOUTINE, M.C. Breeding and selection of sweet potatoes. Journal of Heredity, Washington, D.C., 26(1):3-10, 1935. 